\title{
A queima das pastagens naturais - efeitos sobre o solo e a vegetação
}

\author{
Fire on native pastures - efects on soil and vegetation
}

\author{
Aino Victor Avila Jacques ${ }^{1}$
}

- REVISÃO BIBLIOGRÁFICA -

\section{RESUMO}

Os efeitos do fogo e de alternativas de manejo sobre o solo e vegetação de pastagens naturais foram revisados a partir de diversos trabalhos, juntando observações pessoais desenvolvidas por quase quarenta anos em regiões campestres do Rio Grande do Sul, Brasil. Parâmetros do solo como: acidez potencial; teores de alumínio; saturação de bases e outros foram considerados com parâmetros da vegetação como: produção e qualidade da matéria seca da forragem verde ao longo do ano; composição botânica; quantidade volumétrica de água no solo; ciclagem de nutrientes através da forragem $e$ do mantilho, etc. A conclusão geral, à luz dos resultados dos trabalhos revisados, é de que a queima das pastagens naturais, na região dos campos de altitude sulbrasileiros, deve ser evitada como prática rotineira, pois deteriora as condições do solo, reduz o potencial produtivo e a qualidade da vegetação nativa, e não é uma prática sustentável.

Palavras-chave: fogo, pastagem nativa, manejo.

\section{ABSTRACT}

The effects of fire and alternative managements on soil and vegetation of native pastures were revised from several research works, jointing personal observations developed during almost 40 years in range areas of Rio Grande do Sul, Brazil.
Soil parameters such as potential acidity; aluminum concentration; basis saturation; and others were considered with vegetation parameters such as production and quality of green forage dry matter during the year; botanical composition; volumetric amount of water in soil; nutrients cycling through the forage and dead material; etc. The general conclusion based on the results of the revised works, is that the burning of natural pastures, in the high altitude region of Southern Brazil, must be avoided as a routine practice, because it is detrimental to the environment, reduces the forage yield and quality, and it is not a sustainable practice.

Key words: fire, natural pasture, management.

\section{INTRODUÇÃO}

O fogo tem sido um agente modificador do ambiente desde os estádios de formação da terra. Utilizado em algumas regiões do mundo e proibido em outras, tem dado motivo para uma grande polêmica. $\mathrm{Na}$ Europa Continental, o uso do fogo, como controle da vegetação, é proibido. Na Inglaterra, era permitido em

${ }^{1}$ Engenheiro Agrônomo, PhD., Professor Titular. Colaborador Convidado do Departamento de Plantas Forrageiras e Agrometeorologia da Universidade Federal do Rio Grande do Sul (UFRGS), CP 776, 90001-970, Porto Alegre - RS. Pesquisador do CNPq. E-mail: aino@vortex.ufrgs.br. Autor para correspondência. 
condições muito especiais para controle de certas doenças. Recentemente, com o uso de novas alternativas, também está proibido.

Em nosso meio, ainda é uma questão muito discutida. Combatido por alguns e defendido por outros, o assunto vem sendo encarado com certa indiferença e pouco interesse pelo poder público que, por sua vez, destina poucos recursos para pesquisa e experimentação. No caso das pastagens naturais, quais seriam os motivos para a utilização desta prática? E quais seriam os possíveis benefícios? Os motivos estariam relacionados com a eliminação do material vegetal crestado pelas geadas durante o inverno, cujo excesso, segundo os produtores, prejudicaria a rebrota na primavera. Outra razão invocada é de que os animais (ruminantes e eqüinos) não consumiriam o pasto seco envelhecido e atingido pelas geadas. Quanto à necessidade de eliminação do material seco, após algumas décadas de observação numa propriedade situada na região dos campos de cima da serra, acreditamos que não há necessidade de eliminar o pasto seco com fogo, no caso de espécies de porte baixo, e quando é exercido um certo controle da vegetação existente. Pois este material seco (palha) funciona como proteção da nova brotação que surge no fim do inverno e início da primavera, que promove a renovação da pastagem. Além da proteção das gemas responsáveis pela brotação, a palha, constituída pelas folhas velhas e mortas, desprendida das plantas, cobre a superfície do solo, proporcionando maior retenção de água. Basta verificar a diferença entre um solo coberto com palha e outro descoberto durante uma estiagem. Este benefício é muito bem conhecido pelos lavoureiros que usam o sistema de plantio direto. Este sistema faz, na verdade, a apologia da palha. Mas, os pecuaristas, de um modo geral, ainda não perceberam tal vantagem. No caso das pastagens nativas, o plantio direto acontece naturalmente. Entretanto, é preciso manejar bem a pastagem para que o excesso de material seco não seja demasiado.

Outros assuntos que mereceram atenção foram o grau de infestação de espéceis indesejáveis em áreas queimadas e não queimadas e a velocidade da rebrota das espécies forrageiras após a queima. Num estudo que serviu de base para uma dissertação de mestrado, foi verificado que o Eryngium, uma espécie indesejável, aumentou sua participação em áreas queimadas e a grama forquilha (Paspalum notatum) demorou quatro meses para atingir o nível de rebrota das áreas não queimadas (FONTANELI \& JACQUES, 1988). Este resultado, relacionado com a rebrota dessa espécie, foi confirmado em outra região do Estado, onde levou mais tempo para recuperação plena, após a queima(FONTANELI et al. 1994).

$\mathrm{O}$ argumento de que a queima renova totalmente a pastagem, possibilitando uma dieta de maior valor nutritivo para os animais, também não tem tido amparo científico. BRÂNCIO et al. (1997) verificaram que não havia diferença entre as dietas de animais mantidos em áreas de pastagens queimadas e áreas não queimadas, utilizando fístulas esofágicas para avaliar o que realmente era consumido pelos animais em estudo. Isto porque, havendo boa oferta de forragem, o animal seleciona muito bem a sua dieta, consumindo o que lhe convém. Em outro trabalho (CASTILHOS, 1984) foi verificado que a vantagem da disponibilidade de material verde ocorre por períodos relativamente curtos em comparação com áreas não queimadas, o que não compensaria os prejuízos da prática das queimadas.

Observações pessoais ao longo de quase 40 anos (JACQUES, 1997; JACQUES, 2002) revelam que existem, de fato, dois tipos de queima: uma é a queima do material seco ainda preso à parte aérea da planta e a outra é a queima do mantilho ou material morto já desprendido da planta e depositado sobre a superfície do solo. No primeiro caso, a remoção da parte seca pela ação do fogo representa uma situação semelhante ao que é feito, em grande parte, com a roçadeira. Com o segundo tipo de queima ocorre a eliminação total ou parcial do material seco depositado sobre a superfície do solo, chamado de mantilho ou material morto. Na nossa opinião, a queima exclusiva da parte aérea acarretaria menores prejuízos ao solo e à vegetação, desde que o material queimado (cinza) permanecesse na superfície do solo. Isto é, não fosse arrastado pelas águas das chuvas. Entretanto, esta condição é inevitável na maioria dos casos nas situações de relevos ondulados e acidentados (encostas). Com relação ao segundo tipo de queima de material vegetal, a situação é mais crítica e resulta em maiores prejuízos ao solo e à vegetação. Quanto ao solo, é sabido que uma condição de menor cobertura possui menor capacidade para reter água (SARAIVA et al. (1981). E este é um dos efeitos das queimadas com o qual a maioria dos pesquisadores concorda. Isto é, campo queimado tem maior percentual de solo descoberto. Conseqüentemente, sofre mais com as estiagens. Esta já seria uma boa razão para não utilizarmos a prática das queimadas dos campos nativos.

Não há dúvida de que o efeito do fogo e a temperatura que pode ser atingida na superfície dependem da quantidade de material combustível e das condições ambientais. Mas, em princípio, quando é 
usada a queima é porque tem o que queimar. Isto é, porque existe boa quantidade de material combustível. A questão da temperatura atingida pelo efeito do fogo tem sido estudada por alguns autores. CESAR (1980), citado por COUTINHO (1994), observou temperatura de $280^{\circ} \mathrm{C}$ a $1 \mathrm{~cm}$ de profundidade do solo. Em outros trabalhos, citados por COUTINHO (1994), as temperaturas na superfície variaram de $52-56^{\circ} \mathrm{C}$ até $800^{\circ}$ C. Aqui também vale ressaltar que espécies prostradas (rasteiras) sofrem mais os efeitos do fogo que espécies cespitosas (touceiras) que são, naturalmente, mais protegidas. Entretanto, as cespitosas não são necessariamente as mais nobres.

\section{DESENVOLVIMENTO}

HERINGER (2000) estudou o efeito do fogo por longo período sobre parâmetros do solo e vegetação de uma pastagem natural, na região dos campos de cima da serra, RS. Foram utilizados os seguintes tratamentos ou alternativas de manejo, sob condições de pastejo: sem queima e sem roçada há 32 anos; roçada anual há 32 anos; melhoramento da pastagem nativa há 7 anos; melhoramento da pastagem nativa há 24 anos; e queima bienal há mais de 100 anos. O melhoramento consistiu da aplicação de calcário e adubação e da sobressemeadura de espécies de estação fria e roçada anual. Suas conclusões são as seguintes: A queima resulta em maiores teores e saturação de alumínio, e maior acidez potencial, bem como menores teores de magnésio na camada superficial do solo. A prática da roçada reduz a acidez potencial e aumenta a saturação de bases na superfície do solo. A correção e adubação do solo, e a roçada, favorecem espécies de maior qualidade, como Paspalum notatum, P. paniculatum e Desmodium incanum. A queima favorece as Andropogôneas e Piptochaetium montevidense em detrimento de gramíneas e leguminosas de hábitos rasteiros, e de ciperáceas, reduzindo a riqueza florística. A queima reduz a produção de forragem verde e de mantilho, e a quantidade volumétrica de água no solo, mantendo uma superfície considerável de solo descoberto. Há maior ciclagem de nutrientes através da forragem e do mantilho das áreas sem queima. A qualidade da forragem da vegetação queimada tende a ser inferior à sem queima e sem roçada há 32 anos, e se equivale nas áreas melhoradas ou roçadas, onde é maior. $\mathrm{O}$ tratamento sem queima e sem roçada há 32 anos tende a ser superior ao da área queimada há mais de 100 anos em todos os parâmetros estudados. Sua conclusão geral é de que a queima das pastagens naturais, na região de altitude dos campos sulbrasileiros, deve ser evitada como prática de manejo rotineira, pois deteriora as características do solo e reduz o potencial produtivo da vegetação nativa.
Considerando os possíveis prejuízos ao solo e à vegetação, é interessante examinar quais seriam as implicações econômicas com a prática das queimadas. E possível apresentar alguns números que poderiam dar uma idéia de parte das perdas efetivas. Em trabalhos que foram realizados por diversos autores (CASTILHOS, 1984; GONZAGA, 1986; FONTANELI, 1986; ESTIVALET JUNIOR, 1997; HERINGER, 2000), além da avaliação da disponibilidade da matéria seca da forragem verde, qualidade da forragem e composição botânica, foi objeto de estudo, a composição química do mantilho ou material seco acumulado durante um ano. Justamente o mantilho ou material seco (palha) que é desconsiderado e queimado pelos produtores. As análises feitas serviram para avaliar o que o referido material poderia representar como fertilizante (adubo orgânico). Somente em equivalente nitrogênio - um adubo caro e que há dependência de importação - foram obtidos, em campos não queimados, de 35 a 163 kg.ha${ }^{1}$.ano ${ }^{-1}$. Equivalente a cerca de 1,5 a 7,0 sacos de uréia. Se for multiplicado o valor mínimo aproximado de 1 a 2 sacos de uréia.ha ${ }^{-1}$ ano $^{-1}$ pelo total da área queimada de pastagens naturais, chega-se a um valor próximo do ganho em adubo orgânico nitrogenado, evitando a prática das queimadas. Ainda, no material seco sujeito à queima não existe somente nitrogênio. Podem ser encontrados também fósforo, potássio, cálcio, magnésio e os micronutrientes essenciais às plantas. Além disso, deve ser salientado o valor intrínseco da matéria orgânica, do ponto de vista físico, químico e biológico.

\section{CONCLUSÃO}

1) A queima resulta em maiores teores e saturação de Alumínio, e maior acidez potencial do solo, bem como menores teores de Magnésio na camada superficial do solo. A prática da roçada reduz a acidez potencial e aumenta a saturação de bases na superfície do solo; 2) a correção e adubação do solo, e a roçada favorecem espécies nativas de maior qualidade, como Paspalum notatum, Paspalum paniculatum e Desmodium incanum; 3) a queima favorece as andropogoneas e Piptochaetium montevidense, em detrimento de gramíneas e leguminosas de hábitorasteiro, e de ciperáceas, reduzindo a riqueza florística; 4) a queima reduz a produção de forragem verde e mantilho (palha sobre a superfície do solo), e a quantidade volumétrica de água no solo, mantendo uma superfície considerável de solo descoberto; 5) há maior ciclagem de nutrientes através da forragem e mantilho das áreas sem queima; 6) a qualidade da forragem da vegetação queimada há mais de 100 anos tende a ser inferior à sem queima e só pastejada, e se equivale nas áreas roçadas e melhoradas, onde é maior; 7) o tratamento sem queima e sem roçada há 32 anos, e só pastejado, tende a ser superior ao tratamento queimado há mais de 100 anos em todos os parâmetros estudados; 8) a grama forquilha (Paspalum notatum) demora de 4 a 5 meses para sua rebrotação completa e para atingir nível semelhante ao das áreas não queimadas; 9) o caraguatá (Eryngium horridum), uma das principais espécies in- 
desejáveis das nossas pastagens, aumenta sua participação nas áreas queimadas. A conclusão geral é que a queima das pastagens naturais, na região dos campos de altitude sulbrasileiros, deve ser evitada como prática de manejo rotineira, pois deteriora as características do solo e reduz o potencial produtivo da vegetação nativa.

\section{ALTERNATIVAS}

O pastejo controlado, em certas épocas, é uma ferramenta de manejo muito eficiente. Assim, é possível a utilização dos ruminantes como instrumento de controle da vegetação, com cargas animais relativamente pesadas, em certas épocas, e com categorias animais que sejam menos prejudicadas com esta prática. QUADROS (1999), estudando a dinâmica vegetacional em pastagem natural submetida à queima ou pastejo, conclui que o pastejo exerce uma influência mais marcante sobre a dinâmica vegetacional que o fogo. Esta observação reforça a idéia de que o pastejo pode determinar mudanças na pastagem para melhor ou para pior, dependendo do critério de uso da mesma e do grau de conhecimento das relações clima-soloplanta-animal.

Existem várias alternativas para as queimadas - as de baixo custo e que, até certo ponto, estariam ao alcance dos produtores, em geral, como ajuste de carga, roçada, diferimento, sobressemeadura de espécies de estação fria, suplementação protéica/ nitrogenada, "banco de proteína" e outras e aquelas mais sofisticadas e mais onerosas que utilizam tecnologias modernas, como introdução de espécies cultivadas de estação fria com uso de máquinas apropriadas e até mesma aviação agrícola. Estas práticas constam da seguinte publicação: "Alternativas para as Queimadas - Comissão de Saúde e Meio Ambiente/ Assembléia Legislativa do Rio Grande do Sul'. Entretanto, todas as alternativas exigem um mínimo de conhecimento a respeito do crescimento das espécies nativas e uma idéia clara sobre os períodos de carência e produção (sazonalidade). Ainda, é fundamental que o produtor exerça o controle da vegetação através do manejo - com períodos de utilização e períodos de descanso das pastagens - o que, em alguns casos, precisa de uma orientação técnica.

\section{REFERÊNCIASBIBLIOGRÁFICAS}

BRÂNCIO, P.A. et al. Avaliação de pastagem nativa dos cerrados submetida à queima anual. 2. Qualidade da dieta de bovinos. Revista Bras Zootec, v.26, n.3, p.438-442, 1997.

COUTINHO, L.M. O uso do fogo em pastagens naturais brasileiras. In : PUIGNAU, J. P. (Ed). Utilización y manejo de pastizales. Montevideo : IICA PROCISUR, 1994. p.159168. (DIÁLOGO XL).

CASTILHOS, Z.M.S. Produção e composição botânica de uma pastagem natural submetida a tratamentos de introdução de trevo vesiculoso Cv. Yuchi (Trifolium vesiculosum SAVI), ceifa e queima. 1984. 109f. Dissertação (Mestrado em Zootecnia/Plantas Forrageiras) PPGZootecnia/Plantas Forrageiras, Universidade Federal do Rio Grande do Sul.

ESTIVALET JUNIOR, C.N.O. Efeitos de ceifa, queima e diferimento sobre a disponibilidade de forragem e composição botânica de uma pastagem natural. 1997. 82f. Dissertação (Mestrado em Zootecnia/Plantas Forrageiras) - Pograma de Pós-graduação em Zootecnia/ Plantas Forrageiras, Universidade Federal do Rio Grande do Sul.

FONTANELI, R.S. Melhoramento de pastagens naturais - introdução de espécies forrageiras de estação fria, ceifa, queima, diferimento e adubação. 1986. 92f. Dissertação (Mestrado em Zootecnia/Plantas Forrageiras) Pograma de Pós-graduação em Zootecnia/Plantas Forrageiras, Universidade Federal do Rio Grande do Sul.

FONTANELI, R.S.; JACQUES, A.V.A. Melhoramento de pastagem natural - ceifa, queima, diferimento e adubação. Revista Soc Bras Zootec, v.17, n.2, p.180-194, 1988.

FONTANELI, R.S. et al. Efeito da ceifa, da queima, do diferimento e da adubação sobre uma pastagem natural. Revista Bras Zoot, v.23, n.5, p.719-29, 1995.

GONZAGA, S.S. Produção e composição botânica de uma pastagem natural submetida a diferentes tratamentos de ceifa, queima, e introdução de espécie cultivada e avaliada sob duas intensidades de pastejo. 1986. 137f. Dissertação (Mestrado em Zootecnia/Plantas Forrageiras) - Pograma de Pós-graduação em Zootecnia/ Plantas Forrageiras, Universidade Federal do Rio Grande do Sul.

HERINGER, I. Efeitos do fogo por longo período e de alternativas de manejo sobre o solo e a vegetação de uma pastagem natural. 2000. 208f. Tese (Doutorado em Zootecnia/Plantas Forrageiras) - Programa de Pós-Graduação em Zootecnia/Plantas Forrageiras, Faculdade de Agronomia, Universidade Federal do Rio Grande do Sul.

HERINGER, I.; JACQUES, A.V.A. Características de um Latossolo Vermelho sob pastagem natural sujeita à ação prolongada do fogo e de práticas alternativas de manejo. Ciência Rural, v.32, n.2, p.309-314, 2002..

HERINGER, I.; JACQUES, A.V.A. Acúmulação de forragem e de material morto em pastagem nativa sob distintas alternativas de manejo em relação às queimadas. Revista Bras Zootec, v.31, n.2, p.599-604, 2002.

JACQUES, A.V.A. Relatório do "dia de campo" do CITE $\mathrm{n}^{\circ}$ 100 (Morro da Vigia). Sítio do Pinheirinho, RST $470 \mathrm{Km} \mathrm{150,}$ André da Rocha, RS. 05/07/97. 1997. 
JACQUES, A.V.A. Sítio do Pinheirinho: uma pequena

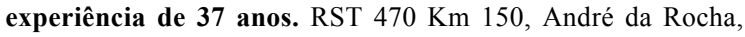
RS. 2002. 9p. (Relatório).

QUADROS, L.F.F. Dinâmica vegetacional em pastagem natural submetida a tratamento de queima e pastejo. 1999. 128f. Tese (Doutorado) - Pograma de Pós-graduação em Zootecnia/Plantas Forrageiras, Universidade Federal do Rio Grande do Sul.

SARAIVA, O.F.; COGO, N.P.; MIELNICZUK, J. Erosividade das chuvas e perdas por erosão em diferentes manejos de solo e coberturas vegetais em solo laterítico bruno avermelhado distrófico (São Jerônimo). II - resultados do segundo ano. Pesq Agropec Bras, Rio de Janeiro, v.16, n.1, p.121-128, 1981.

Ciência Rural, v. 33, n. 1, jan-fev, 2003. 